\title{
Reconsideration of the Safety of Laparoscopic Rectal Surgery for Cancer
}

\author{
Gyung Mo Son ${ }^{1}$, Bong-Hyeon Kye ${ }^{2}$, Min Ki Kim, Jun-Gi Kim ${ }^{3}$ \\ ${ }^{1}$ Department of Surgery, Pusan National University Yangsan Hospital, Pusan National University College of Medicine, Busan; ${ }^{2}$ Department of \\ Surgery, St. Vincent's Hospital, College of Medicine, The Catholic University, Seoul; ${ }^{3}$ Department of Surgery, Myongji Hospital, Hanyang \\ University College of Medicine, Goyang; ${ }^{4}$ Department of Surgery, Seoul St. Mary's Hospital, College of Medicine, The Catholic University of \\ Korea, Seoul, Korea
}

The oncological outcomes of laparoscopic rectal cancer surgery were evaluated in recent multicenter randomized clinical trials (RCTs). The MRC-CLASSIC, COLOR II, and COREAN trials found no differences in local recurrence or diseasefree survival rate between laparoscopic and open surgery. However, the noninferiority of laparoscopic surgery with respect to open surgery for rectal cancer was not established on statistical analysis in the ACOSOG Z6051 and the ALaCaRT trials. Quality of total mesorectal excision (TME) is one of the most important prognostic factors. Incomplete TME had unfavorable oncologic outcomes compared to complete TME. Although TME quality can be clearly identified on pathologic evaluation, there is controversy regarding the acceptable range of oncologically safe TME for laparoscopic surgery. It is not certain whether near-complete TME has an unfavorable oncologic impact and whether laparoscopic surgery with near-complete TME is an oncological threat. Therefore, the surgical community will be interested in the long-term outcomes and meta-analyses of ongoing large-scale RCTs. Laparoscopic rectal cancer surgery has been steadily improving its safety for oncology surgery, which has been reported consistently in various multicenter RCTs. To improve surgical quality, colorectal surgeons should choose the most appropriate surgical technique, including laparoscopic surgery.

\section{Keywords: Laparoscopy; Rectal neoplasms; Surgical procedure; Quality control; Treatment outcome}

\section{INTRODUCTION}

Colorectal cancer is the third most common cancer, and $60 \%$ of these cancers occur in the rectum. Total mesorectal excision (TME) advocated by Heald et al. [1] in 1982 enabled complete resection of rectal cancer and preservation of the pelvic nerve; this has been the standard procedure for rectal cancer treatment for the past 30 years. The quality of TME has been considered one of the most important prognostic factors for long-term oncologic

Received: September 5, 2019 • Accepted: October 16, 2019

Correspondence to: Jun-Gi Kim, Emeritus Professor

Department of Surgery, Seoul St. Mary's Hospital, College of Medicine, The Catholic University of Korea, 222 Banpo-daero, Seocho-gu, Seoul 06591, Korea

Tel: +82-2-2258-2876, Fax: +82-2-595-2822

E-mail: jgkim@catholic.ac.kr

ORCID code: https://orcid.org/0000-0002-4538-4736

(C) 2019 The Korean Society of Coloproctology

This is an open-access article distributed under the terms of the Creative Commons Attribution NonCommercial License (http://creativecommons.org/licenses/by-nc/4.0) which permits unrestricted noncommercial use, distribution, and reproduction in any medium, provided the original work is properly cited. outcomes of patients with rectal cancer. The local recurrence and disease-free survival were significantly different between complete TME and incomplete TME classified according to pathologic assessment [2].

With the introduction of laparoscopic surgery for the surgical treatment of colorectal cancer, astonishing advancements were noted in patient treatment. Laparoscopic surgery has several advantages, i.e., small incisions, less pain, rapid recovery of digestive function, low complication rate, and shorter hospital stay; therefore, it has become the standard procedure for colon cancer surgery [3]. However, some limitations are associated with the use of laparoscopic surgery for rectal cancer in difficult cases, especially when performing radical resection using inflexible laparoscopic surgical instruments in the limited operative field of the narrow pelvis. It is also necessary to achieve a number of important goals, including preservation of anal function and the integrity of adjacent organs, such as the pelvic autonomic nerves. Therefore, laparoscopic rectal cancer surgery should be performed carefully by a laparoscopic expert who has successfully mastered the steep learning curve. 
To investigate the safety of laparoscopic rectal cancer surgery, several large-scale multicenter randomized clinical trials (RCTs) have been conducted. The MRC-CLASSIC, COLOR II, and COREAN trials found no differences in the local recurrence or disease-free survival rate between laparoscopic and open surgery for rectal cancer [4-9]. Therefore, laparoscopic surgery was accepted as a safe operation for rectal cancer.

Recently, there has been controversy regarding the safety of laparoscopic rectal cancer surgery. The ACOSOG Z6051 in the United States (US) and the ALaCaRT trial in Australia and New Zealand failed to demonstrate the noninferiority of laparoscopic surgery using a new composite assessment index of successful resection $[10,11]$. The results of these 2 studies stunned the colorectal cancer surgical community that had been actively expanding laparoscopic procedures for rectal cancer, leading to widespread confusion and debate. The NCCN guideline that had previously recommended laparoscopic colorectal surgery was modified to recommend cautious and limited use by laparoscopic experts [12].

In the current situation of caution, it is necessary to reconsider the safety of laparoscopic rectal cancer surgery. Therefore, we aimed to review the outcomes of laparoscopic rectal cancer surgery reported in recent multicenter RCTs, as well as the efforts being made to overcome the limitations of laparoscopic surgery.

\section{PATHOLOGIC ASSESSMENT OF SURGICAL QUALITY}

TME is considered the most significant innovation in rectal cancer surgery. Prior to the TME era, surgeons used their hands to perform blunt dissections for the removal of rectal cancer tissue within the deep narrow pelvis that inevitably led to local recurrence rates of $45 \%$ or more; these rates were reduced to less than $10 \%$ following the surgical principles of TME [1]. Currently, the local recurrence rates for rectal cancer have been reported to be less than $5 \%$ with the precise application of TME and preoperative chemoradiation therapy (PCRT) [13].

Nagtegaal et al. [2] reviewed TME quality based on pathologic assessments. They found that maintaining the mesorectal envelope was significantly associated with lower local recurrence rates. When the surface of the removed mesorectum had severe defects and the rectal muscle layer was exposed, this was classified as incomplete TME. The risk of local recurrence and circumferential margin involvement was significantly greater in the incomplete TME group.

In the $\mathrm{CAO} / \mathrm{ARO} / \mathrm{AIO}-04$ phase 3 trial conducted in Germany, the long-term prognosis of rectal cancer patients was evaluated according to TME plane. There was a significant difference in 3 -year disease-free survival $(\mathrm{P}=0.01)$, local recurrence $(\mathrm{P}<0.01)$, and distant recurrence $(\mathrm{P}=0.03)$ among mesorectal, intermesorectal, and muscularis propria groups. The interesting finding was that the concordance rate for TME quality between the patholo- gist and surgeon was only $56.2 \%-86.4 \%$. The TME quality evaluation by the pathologist was indicative of the survival rate, but the surgeon's evaluation of TME quality was not related to survival and recurrence. Based on the pathological concordance of the TME studies, this trial reported that pathologists could evaluate surgical quality using objective pathologic assessment to improve the safety of laparoscopic surgery for patients with rectal cancer [14].

Proceeding beyond the controversy regarding surgical techniques for obtaining superior TME quality, we must now consider more important pathologic factors related to long-term oncologic outcomes to design optimal therapeutic strategies for patients with rectal cancer. Successful resection is essential to reduce local recurrence and promote disease-free survival rates, and the most important impact factor among pathologic indicators is circumferential margin involvement [15]. The risk of circumferential margin involvement is associated with tumors closer to the anus and those with higher $\mathrm{T}$ and $\mathrm{N}$ stage. Locally advanced rectal cancer that is poorly responsive to PCRT is thought to be an independent predictor of radial margin involvement [16]. Rectal cancer with a positive radial margin was also associated with poor differentiation, lymphovascular invasion, and extramural vascular invasion, which are characteristics of aggressive tumor biology.

Circumferential marginal involvement is more dependent on aggressive tumor biology than on laparoscopic or open surgery $[16,17]$. Therefore, in mid to low rectal cancer with high risk of recurrence, it is important to pre-evaluate the complete resection potential using preoperative magnetic resonance imaging (MRI) and to determine the appropriate treatment strategy with a multidisciplinary approach. If the radial margin is threatened even after appropriate PCRT, an extended radical resection, such as extralevator abdominoperineal resection (APR) or total neoadjuvant treatment should be considered [18]. In particular, it can be very difficult to perform extended radical resection beyond the TME plane under laparoscopic surgery, which should be performed by highly experienced laparoscopic surgeons to ensure patient safety. Therefore, for patients with a high risk of recurrence, it may be necessary to carefully choose the most appropriate method that allows safe resection, considering the therapeutic strategies involved in a multidisciplinary approach.

Until long-term oncologic outcomes from ongoing RCTs are reported, controversy over the safety of laparoscopic rectal cancer surgery is expected to persist. Till solid evidence is available, it is necessary to choose the most oncologically safe procedure for complete resection based on the experience of the operator, the technology and equipment available at the hospital.

\section{MULTICENTER LARGE-SCALE RCTS FOR LAPAROSCOPIC RECTAL CANCER SURGERY}

There has been a long-standing controversy regarding whether laparoscopic TME can be used safely for patients with rectal can- 
cer while obtaining the advantages of minimally invasive surgery. Rectal cancer surgery is technically demanding; consequently, rectal cancer has often been excluded from studies evaluating the efficacy of laparoscopic surgery.

In recent decades, large-scale multicenter RCTs have been conducted to evaluate the safety of laparoscopic rectal cancer surgery (Table 1).

The MRC-CLASSIC trial was one of the first multicenter RCTs to compare open and laparoscopic colorectal cancer surgeries in the UK [4]. There was no significant difference in terms of circumferential margin involvement between open surgery and laparoscopic rectal cancer surgery, including anterior resection and APR. However, on subgroup analysis for anterior resection patients, circumferential margin involvement was more commonly observed in laparoscopic surgery than in open surgery (12\% vs. $6 \%, \mathrm{P}=0.19)$. This result was a potential landmine that threatened the perception of laparoscopic rectal cancer surgery as safe. However, the long-term oncologic outcomes noted after 5 and 10 years of follow-up indicated that there were no significant differences in local recurrence and disease-free survival rates based on circumferential margin involvement $[7,8]$. As the study was designed to include patients with both rectal and colon cancer, statistical power for comparing open and laparoscopic surgery for rectal cancer was limited.

The COLOR II trial was an international multicenter RCT involving thirty European countries and South Korea, and patients with stage I-III rectal cancer were enrolled [5]. In this trial, TME quality and circumferential margin involvement were not signifi-

Table 1. Characteristics of multicenter RCTs for laparoscopic rectal cancer surgery

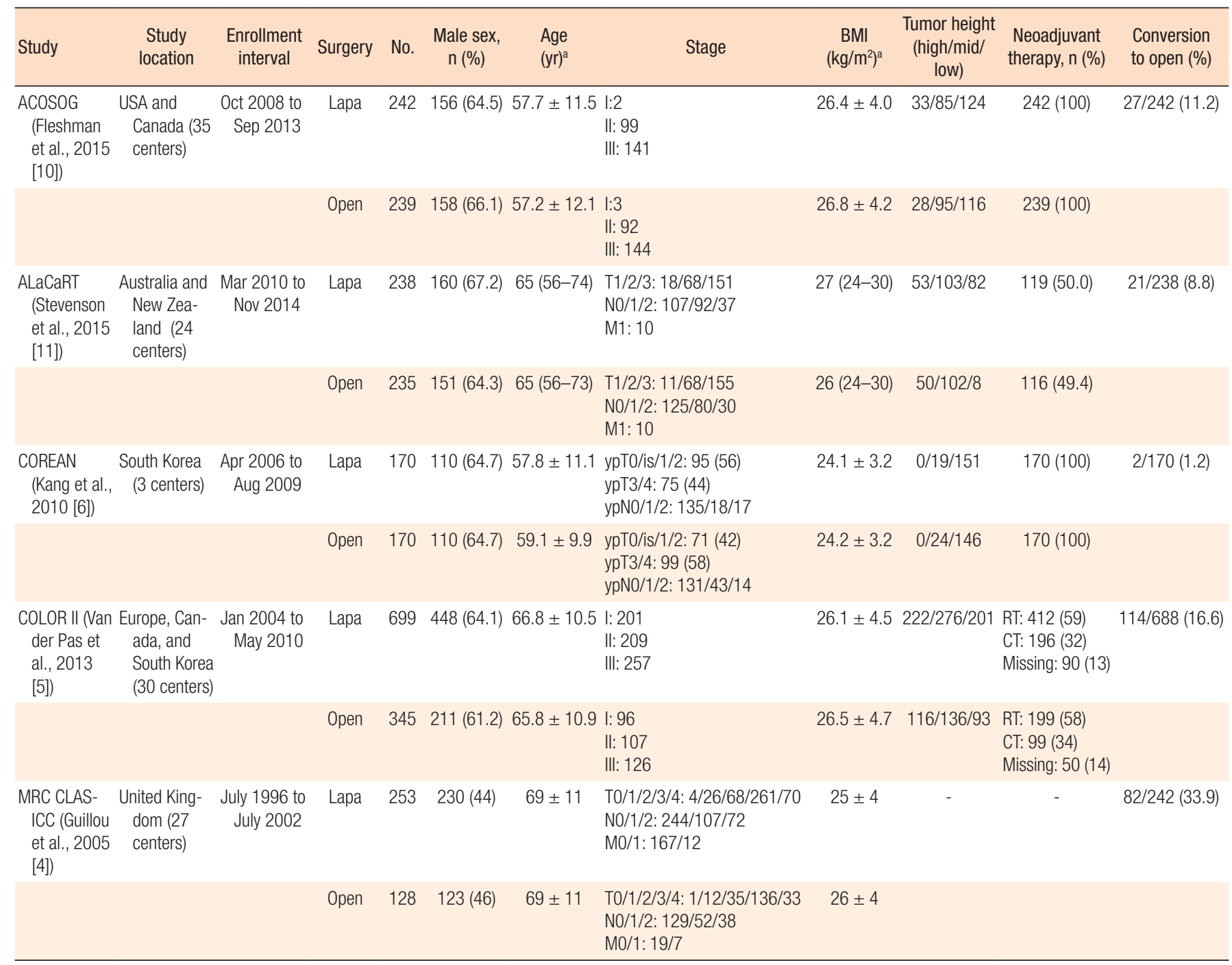

RCTs, randomized controlled trials; BMI, body mass index; Lapa, laparoscopic surgery; RT, radiotherapy; CT, chemotherapy.

aMean \pm standard deviation or median (range). 


\section{$\begin{array}{rlr}\text { Colopnals of } & \text { Reconsideration of the } \\ \text { Colology } & \text { Gyung Mo Son, et al. }\end{array}$}

cantly different between laparoscopic and open surgery (Table 2). With respect to long-term outcomes, local recurrence and disease-free survival rates were also not significantly different between laparoscopic and open surgery (Table 3). Therefore, the COLOR II trial demonstrated the safety of laparoscopic surgery for rectal cancer. However, the limitations of the study included heterogeneity among patient characteristics, and patients who presented with various stages of cancer and more than $30 \%$ of the patients had upper rectal cancer [9]. Therefore, more detailed research on patients with mid to low rectal cancer who received PCRT is required.

The COREAN trial included patients with mid and low rectal cancer of stage II-III who had received PCRT [6]. Complete TME was achieved in approximately $90 \%$ of the patients in the laparoscopic and open surgery groups, and circumferential margin involvement was as low as approximately $5 \%$. Therefore, laparo-

Table 2. Pathologic outcomes of multicenter RCTs for laparoscopic rectal cancer surgery

\begin{tabular}{|c|c|c|c|c|c|c|c|c|c|}
\hline \multirow{2}{*}{ Study } & \multicolumn{5}{|c|}{ TME quality } & \multicolumn{2}{|c|}{ Distal resection margin } & \multicolumn{2}{|c|}{ Circumferential margin } \\
\hline & Complete & Nearly complete & Incomplete & Unknown & P-value & Negative & P-value & Negative (\%) & P-value \\
\hline \multicolumn{10}{|c|}{ ACOSOG (Fleshman et al., 2015 [10]) } \\
\hline Lapa $(n=240)$ & $175(72.9)$ & $46(19.1)$ & $19(7.9)$ & - & - & $98.3 \%$ & 0.910 & 87.9 & 0.110 \\
\hline Open $(n=222)$ & $181(81.5)$ & $30(13.5)$ & $11(4.9)$ & - & & $98.2 \%$ & & 92.3 & \\
\hline \multicolumn{10}{|c|}{ ALaCaRT (Stevenson et al., 2015 [11]) } \\
\hline Lapa $(\mathrm{n}=238)$ & $206(87)$ & $24(10)$ & $8(3)$ & - & 0.060 & $99.0 \%$ & 0.670 & 93.0 & 0.060 \\
\hline Open $(n=235)$ & $216(92)$ & $17(7)$ & $2(1)$ & - & & $99.0 \%$ & & 97.0 & \\
\hline \multicolumn{10}{|c|}{ COREAN (Kang et al., 2010 [6]) } \\
\hline Lapa $(n=170)$ & $123(72.4)$ & $33(19.4)$ & $8(4.7)$ & $6(3.5)$ & 0.414 & $2(1.0-3.5) \mathrm{cm}$ & 0.543 & 97.1 & 0.770 \\
\hline Open $(n=170)$ & $127(74.7)$ & $23(13.5)$ & $11(6.5)$ & $9(5.3)$ & & $2(1.0-3.5) \mathrm{cm}$ & & 95.9 & \\
\hline \multicolumn{10}{|c|}{ COLOR II (Van der Pas et al., 2013 [5]) } \\
\hline Lapa $(\mathrm{n}=699)$ & $589(89)$ & $58(9)$ & $19(3)$ & $33(5)$ & 0.250 & $3(2.0-4.8) \mathrm{cm}$ & 0.676 & 93.0 & 0.850 \\
\hline Open $(n=345)$ & $303(92)$ & $19(6)$ & $9(3)$ & $14(4)$ & & $3(1.8-5.0) \mathrm{cm}$ & & 91.0 & \\
\hline \multicolumn{10}{|c|}{ MRC CLASICC (Guillou et al., 2005 [4]) } \\
\hline Lapa $(n=253)$ & $196(77)$ & - & $33(13)$ & $24(9)$ & - & - & - & 16.0 & 0.800 \\
\hline Open $(n=128)$ & $84(66)$ & - & $31(24)$ & $13(10)$ & - & - & - & 14.0 & \\
\hline
\end{tabular}

Values are presented as number (\%) unless otherwise indicated.

RCTs, randomized controlled trials; Lapa, laparoscopic surgery; TME, total mesorectal excision.

Table 3. Long-term outcomes of multicenter RCTs for laparoscopic rectal cancer surgery

\begin{tabular}{|c|c|c|c|c|c|c|c|c|}
\hline Study & $\mathrm{F} / \mathrm{U}$ & Surgery & OS $(\%)$ & P-value & DFS (\%) & P-value & LR (\%) & P-value \\
\hline \multirow[t]{2}{*}{ ACOSOG (Fleshman et al., 2019 [20]) } & 2 Year & Lapa $(n=242)$ & - & - & 79.5 & 0.771 & 2.1 & 0.860 \\
\hline & & Open $(n=239)$ & - & - & 83.2 & & 1.8 & \\
\hline \multirow[t]{2}{*}{ COREAN (Jeong et al., 2014 [19]) } & 3 Year & Lapa $(n=170)$ & 91.7 & NS & 79.2 & NS & 2.6 & NS \\
\hline & & Open $(n=170)$ & 90.4 & & 72.5 & & 4.9 & \\
\hline \multirow[t]{2}{*}{ COLOR II (Bonjer et al., 2015 [9]) } & 3 Year & Lapa $(\mathrm{n}=699)$ & 86.7 & NS & 74.8 & NS & 5 & NS \\
\hline & & Open $(n=345)$ & 83.6 & & 70.8 & & 5 & \\
\hline \multirow[t]{2}{*}{ MRC CLASICC (Guillou et al., 2005 [4]) } & 3 Year & Lapa $(n=253)$ & 68.4 & 0.550 & 66.3 & 0.700 & 7.8 & 0.700 \\
\hline & & Open $(n=128)$ & 66.7 & & 67.7 & & 7.0 & \\
\hline \multirow[t]{2}{*}{ MRC CLASICC (Jayne et al., 2010 [7]) } & 5 Year & Lapa $(n=253)$ & 60.3 & 0.132 & 53.2 & 0.953 & 9.4 & 0.740 \\
\hline & & Open $(n=128)$ & 52.9 & & 52.1 & & 7.6 & \\
\hline \multirow[t]{2}{*}{ MRC CLASICC (Green et al., 2013 [8]) } & 10 Year & Lapa $(\mathrm{n}=253)$ & 82.7 & 0.780 & 77.0 & 0.589 & - & NS \\
\hline & & Open $(n=128)$ & 78.3 & & 89.5 & & & \\
\hline
\end{tabular}

RCTs, randomized controlled trials; F/U, follow-up; Lapa, laparoscopic surgery; OS, overall survival; DFS, disease free survival; LR, local recurrence; NS, nonsignificance. 
scopic surgery was reported to be as safe as open surgery for the treatment of locally advanced mid and low rectal cancer [19]. Although the homogeneous patient population was randomly assigned to the surgical groups, the response to PCRT was favorable in the laparoscopic group. Although excellent results were obtained in the laparoscopic surgery group, laparoscopic surgery was performed by a small number of highly experienced laparoscopic surgeons; therefore, careful interpretation is required prior to generalizing laparoscopic surgery safety and efficacy within the surgical community.

The surgical societies paid attention to the results of the ACOSOG Z6051 and ALaCaRT trials, both of which were largescale multicenter RCTs performed with a similar methodology; these trials were conducted during the same time period as the COREAN trial $[10,11]$. Both studies included more than 30 institutions and approximately 40 operators. The ACOSOG Z6051 trial was launched to determine whether laparoscopic surgery can safely be used to treat patients with rectal cancer [10]. This study used a successful resection composite index that combined pathologic TME quality, circumferential margin involvement, and distal resection margin to evaluate the safety of laparoscopic rectal cancer surgery in a short period of time with a smaller number of patients to ensure patient safety. Based on the framework of the ACOSOG Z6051 study in the US, the COREAN trial in Korea and the ALaCaRT trial in Australia and New Zealand were also conducted at about the same time.

The short-term oncologic outcomes reported simultaneously in both the ACOSOG Z6051 and ALaCaRT trials. The complete TME quality was achieved in the approximately $80 \%-90 \%$, similar to the results of the previous COLOR-II and COREAN trials $[10,11]$. The proportion of patients with complete TME was higher in the laparotomy groups; however, there was no significant difference between surgical types. The negative distal resection margins were obtained in all patients. Circumferential margin involvement was also less than $10 \%$. There was no significant difference between laparoscopic and open surgery with respect to the TME quality and resection margins with excellent results. However, the noninferiority of laparoscopic surgery with respect to open surgery for rectal cancer was not established on statistical analysis when the low margin 95\% confidence interval range was $6 \%-8 \%$. Therefore, debates over the results of studies that did not verify the noninferiority of laparoscopic rectal cancer surgery could not be avoided.

The 2 studies had the same research design, but there were some differences in patient characteristics and treatment $[10,11]$. In the ACOSOG Z6051 study, patients with locally advanced rectal cancer located $8 \mathrm{~cm}$ from the anal verge were enrolled, and the PCRT rate was $100 \%$. In the ALaCaRT trial, patients with cancer at stage I-III within 12 or $15 \mathrm{~cm}$ of the anal verge were enrolled, and the PCRT rate was as low as $50 \%$. The criteria for TME quality were also different in the two studies. In the ACOSOG Z6051 study, complete and near-complete TME was considered good quality; in the ALaCaRT trial, only complete TME was considered good TME. With the release of the long-term oncological outcomes of the ACOSOG Z6051 and ALaCaRT trials, the surgical community expects to have more solid evidence for the safety of laparoscopic rectal cancer surgery in oncologic terms [20].

\section{META-ANALYSIS OF LAPAROSCOPIC RECTAL CANCER SURGERY RCTs}

Since the large-scale RCTs had the same study design with some differences in patient characteristics and surgical quality evaluation, a meta-analysis was performed to adjust these differences to obtain more reliable evidence [21]. In a meta-analysis reported in 2017, the difference in TME quality of laparoscopic surgery and open surgery was analyzed using 5 RCTs. They classified both near-complete and incomplete TME as noncomplete TME, which was observed in $13.2 \%$ and $10.4 \%$ of subjects in the laparoscopic and open groups, respectively; the risk ratio for noncomplete mesorectal excision was $1.31(\mathrm{P}=0.02)$. Therefore, they concluded that the risk of noncomplete mesorectal excision was significantly higher after laparoscopic surgery [22]. The authors recommended that laparoscopic rectal cancer surgery should be performed more carefully and selectively and suggested the need for advancements in surgical equipment and platforms to improve TME quality beyond the limitations of laparoscopic surgery. However, in this meta-analysis, questions arose over the classification of noncomplete TME and whether nearly complete TME should be considered unacceptable in terms of TME quality and oncological outcomes.

In another meta-analysis, a different cutoff value for acceptable TME quality was applied. Complete and near-complete TME were reclassified as acceptable quality and the proportions of the acceptable TME were not significantly different between laparoscopic and open surgery. However, the rates of near-complete TME were significantly higher in the laparoscopic surgery group. This was attributed to the mesorectal shearing caused by traction with rigid instruments in the narrow pelvic cavity during laparoscopic TME [23].

Incomplete TME was associated with unfavorable outcomes with respect to local recurrence and disease-free survival compared to complete TME. At 2-year follow-up, for the ACOSOG Z6051 trial (reported in 2019), incomplete TME was associated with higher local recurrence [20]. However, there was no significant difference in the local recurrence and disease-free survival rates between complete TME and near-complete TME [24].

Although TME quality can be clearly identified on pathologic evaluation, there is controversy regarding the acceptable range of safe TME for laparoscopic surgery [25]. The evaluation of surgical quality combined with this pathological evaluation index is not directly indicative of the oncological safety of the procedure. The TME quality may be a useful objective index to evaluate and improve operative quality at various institutions; however, the range 
of safe TME was somewhat different in terms of oncological outcomes. It is not certain whether near-complete TME has an unfavorable oncologic impact and whether laparoscopic surgery with near-complete TME is an oncological threat. Therefore, the surgical community will be interested in the long-term survival results of the ACOSOG and ALaCaRT trials and the meta-analysis of the ongoing large-scale RCTs [26].

\section{STANDARDIZATION OF LAPAROSCOPIC COLORECTAL SURGERY}

Based on the oncologic evidence available to date, we believe that the minor discrepancy in TME quality resulting from the difference in surgical techniques between open surgery and laparoscopic surgery is unlikely to undermine the value of oncologic surgery. Moreover, these assumptions are only valid if TME is performed by an expert with sufficient experience in laparoscopic surgery.

Open conversion is one of the clinical indicators that shows whether the learning curve has been suitably mastered. The MRC-CLASSIC study reported an open conversion rate of more than $30 \%$ in the early period of patient registration, which decreased by $16 \%$ by the end of the study [4]. This suggests that the learning curve effect of surgeons participating in the study can be an uncontrolled confounding variable. In the COLOR II trial, the low conversion rate of $15 \%$ meant that the learning curve for laparoscopic surgery had been successfully mastered. In the COREAN trial, surgery was performed by highly experienced laparoscopic surgeons [6]. Therefore, despite the high level of operative difficulty for patients with advanced mid to low rectal cancer, the open conversion rate was only $1 \%$. In the ACOSOG Z6051 study, most of the researchers who participated had already participated in the COST trial in 2004, and because of the high level of enthusiasm and laparoscopic skill, the open conversion rate was $11 \%$, less than the rates reported in the previous MRC-CLASSIC and COLOR-II trials [10].

In our previous study, a multidimensional analysis was done, based on the following parameters: conversion to laparotomy, intraoperative complications, postoperative complications, reoperations, operative time, and transfusion volumes. The conversion rate was 5.6\%, and the risk factors for conversion were prior abdominal surgery and tumor size. Risk-adjusted cumulative sum analysis showed that case 61 was the peak change point for conversion. The turning point for postoperative complications occurred at case 79 . The operative time and intraoperative transfusion volumes stabilized over cases 61-75. Therefore, we found that surgeons must perform $60-80$ operations to master the learning curve for laparoscopic rectal cancer surgery, based on a multidimensional analysis that included various surgical outcomes [27].

The MCR-CLASSIC and the COLOR II trials have led to the standardization of laparoscopic colorectal surgery in the United
Kingdom and Europe $[4,5]$. Surgical quality control was performed using pathologic TME assessment, and the local recurrence and disease-free survival rates were significantly improved compared to the rates reported before these studies. This encouraging change in Europe greatly influenced colorectal surgeons in the US; a nationwide database established through the national cancer registry project was analyzed to identify current problems. Quality of rectal cancer surgery was assessed based on data from approximately $70 \%$ of the hospitals across the US [28].

Of the surgeons who performed rectal cancer surgery, almost $40 \%$ had never performed sphincter-saving surgery for low rectal cancer. APR was performed in more than $70 \%$ of the cases of low rectal cancer. The penetration rate of laparoscopic rectal cancer surgery was less than $20 \%$. More than $30 \%$ of patients with rectal cancer experienced circumferential margin involvement; this rate was more than 3 times higher than the rate of 10\% in Europe [28]. This report led to an increase in awareness regarding the need to improve surgical quality in the US. Accordingly, the Optimizing the Surgical Treatment of Rectal Cancer consortium was set up to encourage education and research to improve the quality of rectal cancer surgery in US hospitals [29]. With the approval and full support of the American College of Surgeons and the American Cancer Society, surgical training programs and hospital certification procedures were introduced to improve surgical quality and to standardize rectal cancer treatment. Although they attempted to refer to the successful model of laparoscopic rectal cancer surgery in Europe, they established policy goals different from those in Europe, where the quality of surgery was improved through the centralization of hospitals. In the US, they want to improve the quality of surgery and treatment in as many hospitals as possible and optimal care could be provided to all possible patients [30]. In this situation, a large-scale multicenter study, the ACOSOG Z6051 trial, was launched to determine whether laparoscopic surgery can be safely used to treat patients with rectal cancer [10]. The results of the trial are expected to standardize laparoscopic rectal cancer surgery techniques and improve multidisciplinary treatment in the US.

\section{ANAL SPHINCTER-SAVING SURGERY IN LOW RECTAL CANCER}

Many efforts have been made to preserve the anal sphincter in very low rectal cancer. With the understanding of the spreading pathway of low rectal cancer and development of the double stapling technique and intersphincteric resection, the frequency of sphincter preserving surgery has increased rapidly from $20 \%$ to $90 \%$ in the past 20 years [31].

For the first time in Korea, the corresponding author developed Laparoscopic Abdominal Trans-Anal proctosigmoidectomy with colo-anal anastomosis (LATA resection), an advanced laparoscopic surgical technique based on the Transanal Abdominal TransAnal proctosigmoidectomy for low rectal cancer advocated 
by Gerald Mark [31,32].

Laparoscopic surgery enables the surgeon to directly visualize the narrow pelvic cavity and to perform accurate and sharp dissections, while the magnified vision clearly delineates the anatomy, thus permitting a more precise TME [31]. This might be the reason that laparoscopic surgery contributes to comparable or better oncological outcomes for rectal cancer. In particular, the oncologic outcomes could be improved using the laparoscopic approach owing to a magnified view of the pelvis. In our previous study, laparoscopic surgery did not adversely affect the long-term oncological outcome for patients with rectal cancer. Especially, the disease-free survival rate of laparoscopic group was significantly better than that open surgery group among stage III patients. In addition, the local recurrence rate was significantly lower for laparoscopic surgery. This study had limitations in that it involved various changes in rectal cancer treatment because the clinical information of patients recorded over a long period of time was retrospectively evaluated. However, multivariate analysis showed that the oncologic outcomes were similar between laparoscopic surgery and open surgery [31].

In a subsequent study for the safety of anal sphincter-saving surgery, local recurrence and disease-free survival rates of the LATA and low anterior resection group were better than those of the APR group in patients with very low rectal cancer within $8 \mathrm{~cm}$ of the anal verge [32]. Considering the selection bias introduced by the retrospective analysis, the local recurrence rate was higher in the APR group because APR was performed mainly in cases of very low rectal cancers located near the anus and invading the anal sphincter complex.

Recently, in patients with very low rectal cancer who underwent PCRT and laparoscopic intersphincteric resection, the risk of local recurrence was associated with higher T stage on MRI and circumferential margin involvement [18]. This finding suggests that careful selection of treatment strategies is essential in multidisciplinary treatment of very low rectal cancer. Further, extensive resection should be actively considered in very low rectal cancers with suspected radial margin involvements diagnosed by pelvic MRI after PCRT.

\section{PERSPECTIVES}

Several options have been proposed to overcome the limitations of laparoscopic surgery and to improve surgical quality [26, 32]. A bottom-up approach through transanal TME is expected to provide more complete TME in obese male patients with a narrow pelvis and fatty mesorectum; therefore, transanal TME may replace the conventional TME approach currently used to undertake laparoscopic rectal cancer surgery in special patients [33]. The results of the COLOR III trial, a large-scale multicenter RCT for transanal TME, are eagerly anticipated [34].

Robotic surgical techniques can be advantageous for rectal cancer surgery since they involve more sophisticated operations and
Endo Wrist instruments. Therefore, it is expected that the open conversion rate may be reduced with robotic surgery, especially for obese patients with narrow pelvises. The ROLLAR trial compared laparoscopic and robotic rectal cancer surgery and analyzed the open conversion rate as the primary outcome [35]. In this study, the open conversion rate was slightly lower in the robotic group; however, there was no significant difference with respect to the TME quality. Future studies in patients with very low rectal cancer may demonstrate the advantages of robotic surgery for performing complete TME. With the continuing development of atraumatic Endo Wrist instruments, it is expected that delicate dissection in the narrow pelvic cavity may be easily performed during minimally invasive surgery.

\section{CONCLUSION}

The use of laparoscopic rectal cancer surgery has been steadily increasing with its safety in terms of oncologic outcomes having been reported consistently in various multicenter RCTs. To improve surgical quality, colorectal surgeons should choose the most appropriate surgical technique, including laparoscopic surgery, when learning curves have suitably been achieved. The development of a robotic surgical platform and suitable surgical approaches are expected to overcome the limitations of the current laparoscopic technique.

\section{CONFLICT OF INTEREST}

No potential conflict of interest relevant to this article was reported.

\section{ACKNOWLEDGMENTS}

The authors thank MS Kwon for data collection and editing the manuscript.

\section{REFERENCES}

1. Heald RJ, Husband EM, Ryall RD. The mesorectum in rectal cancer surgery--the clue to pelvic recurrence? Br J Surg 1982;69:613-6.

2. Nagtegaal ID, van de Velde CJ, van der Worp E, Kapiteijn E, Quirke P, van Krieken JH, et al. Macroscopic evaluation of rectal cancer resection specimen: clinical significance of the pathologist in quality control. J Clin Oncol 2002;20:1729-34.

3. Janson M, Björholt I, Carlsson P, Haglind E, Henriksson M, Lindholm E, et al. Randomized clinical trial of the costs of open and laparoscopic surgery for colonic cancer. Br J Surg 2004;91:409-17.

4. Guillou PJ, Quirke P, Thorpe H, Walker J, Jayne DG, Smith AM, et al. Short-term endpoints of conventional versus laparoscopicassisted surgery in patients with colorectal cancer (MRC CLASICC trial): multicentre, randomised controlled trial. Lancet 2005; $365: 1718-26$. 
5. van der Pas MH, Haglind E, Cuesta MA, Fürst A, Lacy AM, Hop WC, et al. Laparoscopic versus open surgery for rectal cancer (COLOR II): short-term outcomes of a randomised, phase 3 trial. Lancet Oncol 2013;14:210-8.

6. Kang SB, Park JW, Jeong SY, Nam BH, Choi HS, Kim DW, et al. Open versus laparoscopic surgery for mid or low rectal cancer after neoadjuvant chemoradiotherapy (COREAN trial): short-term outcomes of an open-label randomised controlled trial. Lancet Oncol 2010;11:637-45.

7. Jayne DG, Thorpe HC, Copeland J, Quirke P, Brown JM, Guillou PJ. Five-year follow-up of the Medical Research Council CLASICC trial of laparoscopically assisted versus open surgery for colorectal cancer. Br J Surg 2010;97:1638-45.

8. Green BL, Marshall HC, Collinson F, Quirke P, Guillou P, Jayne DG, et al. Long-term follow-up of the Medical Research Council CLASICC trial of conventional versus laparoscopically assisted resection in colorectal cancer. Br J Surg 2013;100:75-82.

9. Bonjer HJ, Deijen CL, Abis GA, Cuesta MA, van der Pas MH, de Lange-de Klerk ES, et al. A randomized trial of laparoscopic versus open surgery for rectal cancer. N Engl J Med 2015;372:132432.

10. Fleshman J, Branda M, Sargent DJ, Boller AM, George V, Abbas M, et al. Effect of laparoscopic-assisted resection vs open resection of stage II or III rectal cancer on pathologic outcomes: The ACOSOG Z6051 randomized clinical trial. JAMA 2015;314:1346-55.

11. Stevenson AR, Solomon MJ, Lumley JW, Hewett P, Clouston AD, Gebski VJ, et al. Effect of laparoscopic-assisted resection vs open resection on pathological outcomes in rectal cancer: the ALaCaRT randomized clinical trial. JAMA 2015;314:1356-63.

12. Venook AB, Al-Hawary MM, Arain MA, Chen YJ, Ciombor KK, Cohen S. NCCN clinical practice guidelines in oncology: rectal cancer, version 3. J Natl Compr Canc Netw 2019;3:34.

13. Breugom AJ, van Gijn W, Muller EW, Berglund $\AA$, van den Broek $\mathrm{CB}$, Fokstuen T, et al. Adjuvant chemotherapy for rectal cancer patients treated with preoperative (chemo)radiotherapy and total mesorectal excision: a Dutch Colorectal Cancer Group (DCCG) randomized phase III trial. Ann Oncol 2015;26:696-701.

14. Kitz J, Fokas E, Beissbarth T, Ströbel P, Wittekind C, Hartmann A, et al. Association of plane of total mesorectal excision with prognosis of rectal cancer: secondary analysis of the CAO/ARO/AIO04 phase 3 randomized clinical trial. JAMA Surg 2018;153: e181607.

15. Massarweh NN, Hu CY, You YN, Bednarski BK, Rodriguez-Bigas MA, Skibber JM, et al. Risk-adjusted pathologic margin positivity rate as a quality indicator in rectal cancer surgery. J Clin Oncol 2014;32:2967-74.

16. Kim CH, Yeom SS, Kwak HD, Lee SY, Ju JK, Kim YJ, et al. Clinical outcomes of patients with locally advanced rectal cancer with persistent circumferential resection margin invasion after preoperative chemoradiotherapy. Ann Coloproctol 2019;35:72-82.

17. Warrier SK, Kong JC, Guerra GR, Chittleborough TJ, Naik A, Ramsay RG, et al. Risk factors associated with circumferential re- section margin positivity in rectal cancer: a binational registry study. Dis Colon Rectum 2018;61:433-40.

18. Park JS, Park SY, Kim HJ, Cho SH, Kwak SG, Choi GS. Long-term oncologic outcomes after neoadjuvant chemoradiation followed by intersphincteric resection with coloanal anastomosis for locally advanced low rectal cancer. Dis Colon Rectum 2019;62:408-16.

19. Jeong SY, Park JW, Nam BH, Kim S, Kang SB, Lim SB, et al. Open versus laparoscopic surgery for mid-rectal or low-rectal cancer after neoadjuvant chemoradiotherapy (COREAN trial): survival outcomes of an open-label, non-inferiority, randomised controlled trial. Lancet Oncol 2014;15:767-74.

20. Fleshman J, Branda ME, Sargent DJ, Boller AM, George VV, Abbas MA, et al. Disease-free survival and local recurrence for laparoscopic resection compared with open resection of stage II to III rectal cancer: follow-up results of the ACOSOG Z6051 randomized controlled trial. Ann Surg 2019;269:589-95.

21. Arezzo A, Passera R, Salvai A, Arolfo S, Allaix ME, Schwarzer G, et al. Laparoscopy for rectal cancer is oncologically adequate: a systematic review and meta-analysis of the literature. Surg Endosc 2015;29:334-48.

22. Martínez-Pérez A, Carra MC, Brunetti F, de’Angelis N. Pathologic outcomes of laparoscopic vs open mesorectal excision for rectal cancer: a systematic review and meta-analysis. JAMA Surg 2017; 152:e165665.

23. Milone M, Manigrasso M, Burati M, Velotti N, Milone F, De Palma GD. Surgical resection for rectal cancer. Is laparoscopic surgery as successful as open approach? A systematic review with meta-analysis. PLoS One 2018;13:e0204887.

24. Creavin B, Kelly ME, Ryan E, Winter DC. Meta-analysis of the impact of surgical approach on the grade of mesorectal excision in rectal cancer. Br J Surg 2017;104:1609-19.

25. Cleary RK, Morris AM, Chang GJ, Halverson AL. Controversies in surgical oncology: does the minimally invasive approach for rectal cancer provide equivalent oncologic outcomes compared with the open approach? Ann Surg Oncol 2018;25:3587-95.

26. Fleshman J. Current status of minimally invasive surgery for rectal cancer. J Gastrointest Surg 2016;20:1056-64.

27. Son GM, Kim JG, Lee JC, Suh YJ, Cho HM, Lee YS, et al. Multidimensional analysis of the learning curve for laparoscopic rectal cancer surgery. J Laparoendosc Adv Surg Tech A 2010;20:609-17.

28. Monson JR, Probst CP, Wexner SD, Remzi FH, Fleshman JW, Garcia-Aguilar J, et al. Failure of evidence-based cancer care in the United States: the association between rectal cancer treatment, cancer center volume, and geography. Ann Surg 2014;260: 625-31.

29. Dietz DW; Consortium for Optimizing Surgical Treatment of Rectal Cancer (OSTRiCh). Multidisciplinary management of rectal cancer: the OSTRICH. J Gastrointest Surg 2013;17:1863-8.

30. Abbas MA, Chang GJ, Read TE, Rothenberger DA, Garcia-Aguilar J, Peters W, et al. Optimizing rectal cancer management: analysis of current evidence. Dis Colon Rectum 2014;57:252-9.

31. Kim JG, Heo YJ, Son GM, Lee YS, Lee IK, Suh YJ, et al. Impact of 
laparoscopic surgery on the long-term outcomes for patients with rectal cancer. ANZ J Surg 2009;79:817-23.

32. Kye BH, Kim JG, Cho HM, Kim HJ, Chun CS. Laparoscopic abdominal transanal proctocolectomy with coloanal anastomosis is a good surgical option in selective patients with low-lying rectal cancer: a retrospective analysis based on a single surgeon's experience. J Laparoendosc Adv Surg Tech A 2018;28:269-77.

33. de Lacy AM, Rattner DW, Adelsdorfer C, Tasende MM, Fernán$\operatorname{dez}$ M, Delgado S, et al. Transanal natural orifice transluminal endoscopic surgery (NOTES) rectal resection: "down-to-up" total mesorectal excision (TME)--short-term outcomes in the first 20 cases. Surg Endosc 2013;27:3165-72.

34. Deijen CL, Velthuis S, Tsai A, Mavroveli S, de Lange-de Klerk ES, Sietses C, et al. COLOR III: a multicentre randomised clinical trial comparing transanal TME versus laparoscopic TME for mid and low rectal cancer. Surg Endosc 2016;30:3210-5.

35. Jayne D, Pigazzi A, Marshall H, Croft J, Corrigan N, Copeland J, et al. Effect of robotic-assisted vs conventional laparoscopic surgery on risk of conversion to open laparotomy among patients undergoing resection for rectal cancer: the ROLARR randomized clinical trial. JAMA 2017;318:1569-80. 